\title{
Assessment of level of adherence to anti retroviral therapy among adult HIV infected patients in Mekelle Hospital, northern Ethiopia
}

\author{
Afewerki Kahsay Kidanemariam ${ }^{1}$, Gebremedhin Gebreegziabiher Gebrehiwot ${ }^{2,}$, \\ ${ }^{1}$ Tigray Regional Health Beareau, HIV prevention and control case team, Mekelle, Ethiopia \\ ${ }^{2}$ Adigrat Univerity, College of Medicine and Health Sceinces, department of Public Health, Adigrat, Ethiopia
}

Email address:

afeworki.kahsay@yahoo.com (A. Kahsay),ghingherg@yahoo.com (G. Gebreegziabiher)

\section{To cite this article:}

Afewerki Kahsay Kidanemariam, Gebremedhin Gebreegziabiher Gebrehiwot. Assessment of Level of Adherence to Anti Retroviral Therapy among Adult HIV Infected Patients in Mekelle Hospital, Northern Ethiopia. Clinical Medicine Research. Vol. 4, No. 2, 2015 , pp. 50-57. doi: $10.11648 /$ j.cmr.20150402.15

\begin{abstract}
Introduction: HIV/AIDS is one of the most destructive epidemics the world has ever witnessed. Non-adherence to the proposed antiretroviral regimen is considered to be one of the greatest dangers to the response to treatment on an individual level and the dissemination of resistant viruses on the community level. An adherent patient is defined as one who takes $>95 \%$ of the prescribed doses. Objective: To assess the level of adherence and associated factors among adult HIV/AIDS patients receiving Highly Active Antiretroviral Therapy in Mekelle Hospital, Northern Ethiopia. Methods: A cross sectional study was carried out from January 1, 2013 to July 30, 2013 among 382 adult PLWHA (>=18 years) attending HAART clinic at Mekelle Hospital. Data was collected by a combination of structured questionnaire and document review. The data was entered and cleaned using Epi-Info; transported to SPSS 16.0 version for final analysis. Bivariate and multivariate analyses were performed to identify factors associated with adherence. Results: The rate of self reported adherence in the study based on the Schedule and indicator of the dose, time measurement in the last 7 days was $(78.3 \%)$. Females were more adhered than males (185(87.7\%)). Alcohol users have poor adherence than non alcohol users with $70.5 \%$ and $82.2 \%$ level of adherence respectively. Sex and educational status of the study participants were significantly associated with level of adherence with AOR $(95 \%$ CI $)$ of 3.81 $(2.18,6.69)$ and $2.60(1.43,4.71)$ respectively. Conclusion: The level adherence we found, $78.2 \%$, is still very low considering the WHO recommendation of $95 \%$. Sex and educational status of the study participants were significantly associated with level of adherence with AOR $(95 \% \mathrm{CI})$ of $3.81(2.18,6.69)$ and $2.60(1.43,4.71)$ respectively. More focus should be given to males and individuals with low educational status to improve level of adherence and to assure the efficacy of HAART in prolonging the life of PLWHA. Adherence is a process, not a single event, and adherence support must, therefore, be integrated into regular clinical follow up. Investigation of factors related with long-term adherence would require longer follow-up than the present study.
\end{abstract}

Keywords: Adherence, PLWHA, Mekelle Hospital, HIV/AIDS, Adults

\section{Introduction}

HIV/AIDS is one of the most destructive epidemics the world has ever witnessed. In 2007 an estimated 33.2 million people were living with HIV worldwide, while 2.5 million of these people were children under 15 years old [1]. The number of people living with HIV worldwide continued to grow. Sub-Saharan Africa remains the region most heavily affected by HIV. In 2008, sub-Saharan Africa accounted for $67 \%$ of HIV infections worldwide, $68 \%$ of new HIV infections among adults. The region also accounted for $72 \%$ of the world's AIDS-related deaths in 2008 [2]. Ethiopia is home to approximately 800,000 patients with HIV/AIDS and the prevalence of HIV/AIDS in the general population is estimated to be $1.5 \%$. In the past 8 years, decentralization and scale-up of the HIV care programme has occurred and by the end of 2011, 249,174 adult patients (86\% of eligible patients) were on Highly Active Anti-retroviral Therapy (HAART) [3]. In Ethiopia, the antiretroviral treatment program started with a fee-based ART program in 2003 then decentralized and free ART program in the Country was lunched since 2005[4]. 
Adherence to medication is a dynamic behavior affected by factors related to treatment regimen complexity, patientrelated variables, patient-healthcare provider relationships and the quality of healthcare services [5]. Non-adherence to the proposed antiretroviral regimen is considered to be one of the greatest dangers to the response to treatment on an individual level and the dissemination of resistant viruses on the community level [6]. Very high levels of adherence ( $>$ $95 \%$ ) are required for HAART to be effective for long term and to prevent the emergence of resistant viral strains $[7,8]$. An adherent patient is defined as one who takes $>95 \%$ of the prescribed doses [9]. However a significant proportion of HIV-infected patients do not reach high levels of adherence. The principal reasons reported for skipping doses are running out of medication/drug, being away from home, being busy with other things, simply forgetting, having no food to take with the medication, fear of side effect and feeling sick or ill at that time [10].

Little is known about the rate and predictors of adherence in Ethiopia. In line with the above facts, about 720 patients were lost from their treatment since started the program in the study area and also reasons for treatment interruption were not investigated. It is known that development of successful interventions to improve treatment adherence requires understandings of those factors influencing patient's medication taking by performing periodic assessment of level of HAART adherence. Predictors of adherence of Adult on HAART not yet well documented. This study will be helpful to fill the information gap and provide empirical evidence for program planners, decision makers and HAART program implementers at different levels. Therefore, identifying the level and predictors of adherence of adults on HAART will be helpful in planning, implementing and monitoring programs on HAART.

\section{Method}

\subsection{Study Area and Period}

The study was conducted in Mekelle city, Mekelle Hospital, which is located in northern Ethiopia. Mekelle zone is found $783 \mathrm{~km}$ north of the capital city Addis Ababa. A total of 289,587 people with 65,815 households are living in the city (source:- Mekelle city plan and finance office, 2012). Mekelle Hospital is one of the referral hospitals of Tigray regional state found in Mekelle city, capital of the regional state. About 17 professionals and adherence workers have been working in the ART clinic. The hospital gives different curative and preventive services for Mekelle residents and referred patients from other Districts, as well as the neighboring regions of Afar and Amhara. It provides HIV/AIDS related services such as HIV counseling and testing (HCT), TB/HIV collaborative activities, Prevention of Mother to Child Transmission (PMTCT), exposed care, opportunistic infection and Anti-retroviral (ARV) prophylaxis and treatment. In the Hospital, fee based HAART program has been introduced in 2003 and the free
HAART program started in March 2005. A total of 7,350 HIV infected individuals have been enrolled since HAART started in the hospital. About 5,854 are ever started HAART in the hospital. The major justification to consider this hospital as study area was, more than 25\% People Living With HIV/AIDS (PLWHA) under HAART in the Region are attending at this hospital, and it is also the earliest hospital since HAART program has been started in the region. The study were conducted from January 1/ 2013 to July 30/ 2013.

\subsection{Study Design}

Facility based Cross-Sectional study was conducted among PLWHA to assess level of adherence and associated factors to HAART.

\subsection{Sample Size Determination and Sampling Technique}

\subsubsection{Sample Size Determination}

The sample size was calculated by using single population proportion formula with 95\% confidence interval, 50\% level of adherence and margin of error 5\%. The calculation resulted in a sample size of 347 . Ten percent $(10 \%=35)$ of the total sample size were added for any non-response of the study subjects during the study period. The actual sample size of the study was 382 .

$$
\mathrm{n}=\frac{\mathrm{z} 2 \mathrm{p}(1-\mathrm{P})}{\mathrm{d} 2} \text {, Where } \mathrm{z}=1.96
$$

$\mathrm{p}=$ no previous study, so we took the safest choice (50\%).

$$
1-p=1-0.5=0.5
$$

$\mathrm{d}=$ degree of accuracy required

$$
\mathrm{n}=\frac{1.96^{2} * 0.5(1-0.5)}{(0.0025)}=384
$$

$\mathrm{nf}=\frac{\mathrm{n}}{1+\mathrm{n} / \mathrm{N}}$ Where $\mathrm{nf}$-the desired sample size (when total population is less than 10,000).

$\mathrm{N}$-the estimated population size $=3,650$

$$
\mathrm{nf}=\frac{384}{1+384 / 3,650}=347
$$

When we add contingency for non response $=347 \times 10 \%=34.5 \sim 35$ Then $35+347=382$

\subsubsection{Sampling Technique}

Study participants were selected using simple random sampling technique from the ART unique number of those currently on ART in the ART clinic who full filed the Inclusion criteria.

\subsection{Data Collection Tools and Procedures}

Data was collected using structured questionnaire and document review which include the following variables such as socio-demographic characteristics, Knowledge of patients towards treatment and health care system, patients self-report to treatment adherence. 


\subsection{Data Quality Control and Management}

An intensive one-day training session was given for all data collectors and supervisors before data collection. Before commencement of the actual study, the study tools and instruments were pre-tested in Mekelle health center in 5\% of the total sample size and modifications were incorporated to the questionnaire. The interview was conducted in private room to create an atmosphere of empathy and confidence within a secure environment. Data collectors were selected from health workers particularly; Nurses who were previously trained and working on HAART in other health facilities. The overall activity was controlled by the principal investigator of the study and proper designing of the data collection materials and continues supervision during data collection was performed. All completed questionnaires were examined for completeness and consistency during data management, storage and analysis.

\subsection{Data Analysis}

Data was coded, entered in to EPI-info and cleaned before data processing. Data was summarized and analyzed using SPSS 16.0 computer statistical soft ware. Association test was made between the dependent and independent variables. Bivariate and multivariate logistic regression with $95 \%$ Confidence Interval (CI) was calculated. Independent variables found significant at $\mathrm{P}$-value $<0.05$ were entered to multiple logistic regressions to identify independent predictors of adherence after controlling for possible confounding variables. Odds ratios (OR) with their 95\% CI were calculated and data is presented by tables and graphs. All the tests were considered significant at $\mathrm{p}<0.05$ level.

\subsection{Ethical Consideration}

An ethical approval was obtained from the ethical review committee of Mekelle University, college of health sciences, research and community service office. Official Support letter was obtained from Mekelle University, Tigray regional health bureau and Mekelle Hospital for conducting the study. Information about objective of the study, procedures, potential risks and benefits was given to the study participants before they were enrolled to the study. All participants were informed about the purpose and significance of the study to get their consent and their full right to refuse, withdraw or completely reject to be included in the study. Written informed consent was obtained from each study participant selected for the study. The right of participants to anonymity and confidentiality was maintained by making the questionnaire anonymous. The raw data was handled with key and locked system and the information was not handover to third party.

\subsection{Operational Definitions}

1. Treatment adherence: defined as the ability of taking medications as prescribed.

2. Lack of adherence: level below $95 \%$ adherence.
3. Missed dose: any antiretroviral medication missed to take by the patients as prescribed or taking late from the recommended time

4. High adherence /optimal adherence: adherence levels that would be expected to enable successful treatment response that is at least $95 \%$ achievement of adherence.

5. Seriously sick person: a person who is not able to walk without help and or not able to respond to questionnaire.

6. Stable mental condition: patient who doesn't manifest active mental illness.

7. PLWHA: people who disclose their HIV sero- status.

8. CD4 count: a way of measuring immune-competency by counting the lymphocyte that carry the CD4 marker.

9. Viral Load: the quantity of HIV RNA in the blood.

10. STOP: If the patient and the clinician discussed and decided to stop treatment for different reasons.

11. LOST: If the patient has missed an appointment (not picked up drugs) for at least one month

12. DEAD: If the facility has been notified that the patient has died

Table 1. WHO cut off points with regard to level of Adherence.

\begin{tabular}{lll}
\hline & Adherence in \% & Missed doses of 60 doses \\
\hline $\mathrm{G}$ (Good) & $>95 \%$ & $<3$ doses \\
$\mathrm{F}$ (Fair) & $85-94 \%$ & $4-9$ doses \\
$\mathrm{P}$ (poor) & $<85 \%$ & $>9$ doses \\
\hline
\end{tabular}

\section{Result and Discussion}

\subsection{Result}

\subsubsection{Socio-Demographic and Economic Characteristics of Study Participants}

A total of 382 adult PLWHA have been participated in the study giving a response rate of $100 \%$. Out of the 382 PLWHA the largest number, 153 (40.1\%), were in the age group 35-44 years. The mean (SD) age of the study participants was $37.4(8.29)$ ranging from 19 to 65 years and the number of female participants were $211(55.2 \%)$. The majority of the study participants were Tigray ethnic group [369(96.6\%)] and Urban inhabitants [356(93.2\%)]. Majority of the study participants were Orthodox religion followers [363(95.0\%)]; 182(47.6) of the study participants were married or had partners, $22.8 \%$ were widowed, $24.8 \%$ were divorced and $5.5 \%$ were single. The majority of them, 180(47.1\%), had attend elementary school. One hundred eleven (29.1\%) were daily laborers. Majority, 188(49.2), live with their family/partner. Almost more than half, 201(52.6\%), have monthly income of 500 and less Ethiopian birr and the median income of the participants was 500 Ethiopian birr (26 USD) ranged from 100 to 10,000 Ethiopian birr. Most respondents $(97 \%)$ were detected as being HIV positive more than 2year ago. According to self report the most common mode of HIV transmission was through sexual intercourse with their partner or Husbands (42.2\%) (Table2). 
Table 2. Socio-demographic and economic characteristics of the study participants, Mekelle Hospital, Mekelle zone, Northern Ethiopia, $2013(n=382)$.

\begin{tabular}{|c|c|c|c|}
\hline \multirow{2}{*}{ Variable } & \multicolumn{2}{|l|}{ Frequency } & \multirow{2}{*}{$\begin{array}{l}\text { Total- } \\
\mathbf{N}(\%)\end{array}$} \\
\hline & Male - N(\%) & Female - N(\%) & \\
\hline Sex & $171(44.8)$ & 211(55.2) & $382(100)$ \\
\hline \multicolumn{4}{|l|}{ Age } \\
\hline $18-24$ & $2(0.5)$ & $5(1.3)$ & $7(1.8)$ \\
\hline $25-34$ & $49(12.8)$ & $89(23.3)$ & $138(36.1)$ \\
\hline $35-44$ & $81(21.3)$ & $72(18.8)$ & $153(40.1)$ \\
\hline$>=45$ & $39(10.2)$ & $45(11.8)$ & $84(20)$ \\
\hline \multicolumn{4}{|l|}{ Occupation } \\
\hline Gove't employee & $45(11.8)$ & $28(7.3)$ & $73(19.1)$ \\
\hline Merchant & $26(6.8)$ & $51(13.4)$ & $77(20.2)$ \\
\hline Farmer & $12(3.1)$ & $11(2.9)$ & $23(6.0)$ \\
\hline Housewife & $6(1.6)$ & $22(5.7)$ & $28(7.3)$ \\
\hline Daily labourer & $52(13.6)$ & $59(15.5)$ & $111(29.1)$ \\
\hline Have no job & $20(5.2)$ & $37(9.7)$ & $57(14.9)$ \\
\hline Driver & $10(2.6)$ & $3(0.8)$ & $13(3.4)$ \\
\hline \multicolumn{4}{|l|}{ Marital status } \\
\hline Married & $104(27.2)$ & $78(20.4)$ & $182(47.6)$ \\
\hline Single & $14(3.7)$ & $7(1.8)$ & $21(5.5)$ \\
\hline Widowed & $16(4.2)$ & $71(18.6)$ & $87(22.8)$ \\
\hline Divorced & $37(9.7)$ & $55(14.4)$ & $92(24.1)$ \\
\hline \multicolumn{4}{|l|}{ Educational status } \\
\hline $\begin{array}{l}\text { Unable to read and } \\
\text { write }\end{array}$ & $27(7.1)$ & $66(17.2)$ & $93(24.3)$ \\
\hline Primary school(1-8) & $84(22)$ & $96(25.1)$ & $180(47.1)$ \\
\hline $\begin{array}{l}\text { Secondary school(9- } \\
\text { 12) }\end{array}$ & $36(9.4)$ & $36(9.4)$ & $72(18.8)$ \\
\hline Diploma and above & $24(6.3)$ & $13(3.4)$ & $37(9.7)$ \\
\hline \multicolumn{4}{|l|}{ Residence of patient } \\
\hline Rural & $13(3.4)$ & $13(3.4)$ & $26(6.8)$ \\
\hline Urban & $158(41.4)$ & $198(51.8)$ & $356(93.2)$ \\
\hline \multicolumn{4}{|c|}{ Average monthly income } \\
\hline$=<500$ & $79(20.7)$ & $122(31.9)$ & $201(52.6)$ \\
\hline $501-999$ & $22(5.8)$ & $23(6.0)$ & $45(11.8)$ \\
\hline$>=1000$ & $70(18.3)$ & $66(17.3)$ & $136(35.6)$ \\
\hline
\end{tabular}

\subsubsection{Variation in Level of Adherence due to Difference in Socio-Demographic Variables}

Females were more adhered than males with level of adherence $81 \%$ and $74.9 \%$ respectively. More adherence was observed in the middle aged study participants i.e. individuals at the lower and upper age extremities were less adhered. Considering the occupation of the study participants, merchants and daily laborers were lower in level of adherence with $75.3 \%$ and $72.1 \%$ respectively. Lower adherence was observed among single and widowed study participants with 76.2 and 74.7 level of adherence respectively. Considering their educational status, those study participants who can't read and write and those with more level of education (diploma and above) were lower in adherence with $71.0 \%$ and $72.8 \%$ respectively. Urban inhabitants were lower in adherence than rural inhabitants with level of adherence $78.1 \%$ and $80.8 \%$ respectively. Level of adherence was affected by the average monthly income of the study participants. Study participants who have more annual income $(>=1000 \mathrm{EBR})$ were less adhered than those with low annual income with $77.2 \%$ level of adherence. Study participants who live alone were less in adherence $(74.8 \%)$ and those who live with their children were more in level of adherence (85.4\%). Study participants who have a distance of $=<10 \mathrm{~km}$ were more adhered than those who have $>10 \mathrm{~km}$ with level of adherence $80.4 \%$ and $74.2 \%$ respectively.

\subsubsection{Clinical Markers of the Study Participants}

The baseline CD4 count of most of the study participants (73.6\%) were less than 200cells/ul of blood. After enrolled in to HAART, only $15.2 \%$ study participants have CD4 count of less than 200cells/ul. This indicates greater improvement in CD4 count among individuals taking HAART. Almost all of the study participants, (97.4\%), were on first line regimen, of these AZT based AZT,3TC,NVP (42.4\%) and TDF based TDF,3TC,NVP (45.0\%). D4t based were $10 \%$. Only $2.6 \%$ study participants were on second line regimen due to drug resistance and/or some health problems. Only $8.2 \%$ of the study participants were enrolled on HAART for 6-24months; where as $48.4 \%$ enrolled for $2-4$ years period. The rest $43.4 \%$ were under HAART for more than 4 years.

Table 3. Clinical markers of the study participants comparing male and female Level of adherence, Mekelle Hospital, Mekelle zone, Northern Ethiopia, 2013(n=382).

\begin{tabular}{|c|c|c|c|}
\hline \multirow{2}{*}{ Variable } & \multicolumn{2}{|l|}{ Sex } & \multirow{2}{*}{ Total- N(\%) } \\
\hline & Male- N(\%) & Female- N(\%) & \\
\hline \multicolumn{4}{|c|}{ CD4 Count Baseline } \\
\hline$<=200$ & $132(34.6)$ & $149(39)$ & 281(73.6) \\
\hline $201-499$ & $39(10.2)$ & $60(15.7)$ & $99(25.9)$ \\
\hline$>=500$ & $0(0.0)$ & $2(0.5)$ & $2(0.5)$ \\
\hline \multicolumn{4}{|l|}{ Recent CD4 Count } \\
\hline$<=200$ & $32(8.4)$ & $26(6.8)$ & $58(15.2)$ \\
\hline $201-499$ & $89(23.3)$ & $123(32.2)$ & $212(55.5)$ \\
\hline$>=500$ & $50(13.1)$ & $62(16.2)$ & $112(29.3)$ \\
\hline \multicolumn{4}{|c|}{ Duration of Treatment ARV Regimen in months } \\
\hline $6.0-24.0$ & $12(3.1)$ & $19(5.1)$ & $31(8.2)$ \\
\hline 24.1-48.0 & $84(22.0)$ & $101(26.4)$ & $185(48.4)$ \\
\hline$>48.0$ & $75(19.6)$ & $91(23.8)$ & $166(43.4)$ \\
\hline \multicolumn{4}{|c|}{ Current TB treatment status } \\
\hline $\begin{array}{l}\text { Currently on } \mathrm{TB} \\
\text { treatment }\end{array}$ & $35(9.2)$ & $32(8.4)$ & $67(17.6)$ \\
\hline $\begin{array}{l}\text { TB treated in past } \\
3-6 \text { months }\end{array}$ & $6(1.6)$ & $12(3.1)$ & $18(4.7)$ \\
\hline Never treated & $130(34.0)$ & $167(43.7)$ & 297(77.7) \\
\hline \multicolumn{4}{|c|}{ Knowledge on importance of adherence } \\
\hline Yes & $99(25.9)$ & $113(29.6)$ & $212(55.5)$ \\
\hline No & $72(18.8)$ & $98(25.7)$ & $170(44.5)$ \\
\hline \multicolumn{4}{|c|}{ Distance from residence to clinic } \\
\hline$=<10 \mathrm{~km}$ & $134(35.1)$ & $182(47.6)$ & $316(82.7)$ \\
\hline$>10 \mathrm{~km}$ & $37(9.7)$ & $29(7.6)$ & $66(17.3)$ \\
\hline \multicolumn{4}{|c|}{ Disclosure on HIV positive status } \\
\hline Yes & $112(29.3)$ & $138(36.1)$ & $250(65.4)$ \\
\hline No & $59(15.4)$ & $73(19.2)$ & $132(34.6)$ \\
\hline
\end{tabular}

More than three-fourth (77.7\%) of the study participants have never been treated for TB. Only $4.7 \%$ individuals were treated for TB in the last month. Only $17.6 \%$ were currently on TB treatment. Almost half $(44.5 \%)$ of the study participants have no knowledge on importance of adherence. Around $44.2 \%$ individuals have clinical appointments of every month. Half of the individuals, (58.4\%), have no 
missed dose and in one fourth of the study participants (25.9\%), one and above missed dose. The main reason for missed dose was for getting. Around $68.3 \%$ study participants were currently on treatment for opportunistic infection (OI); $6.3 \%$ were treated in the past three months and only $25.4 \%$ individuals never treated for OI. The distance from residence to clinic for most study participants $(82.7 \%)$ was $10 \mathrm{~km}$ or less than that (Table 3$)$.

\subsubsection{Disclosure Status, Social Support Status and Stigma Related Pill Taking}

Considering the disclosure status of the study participants, $65.4 \%$ disclose their HIV positive status to their family member only and $34.6 \%$ of the individuals never disclose their HIV positive status. Around three-fourth (73.8\%) do not get family and social support. Almost more than half of the participants $(52.5 \%)$ have stigma related pill taking. The source of information on availability of HAART treatment given were mass media (24.1\%) and Health providers (75.9\%).

\subsubsection{Self Reported dose/Treatment, Schedule/Program Adherence among the Respondents}

Self reported dose/treatment adherence among the respondents was $78.3 \%$. Indicated reasons for missed appointment were forgetting $31.4 \%$, too busy $11.5 \%$, far distance $3.4 \%$ and felt sick $1 \%$. Majority of the study participants, $53.9 \%$, use clock alarm as adherence aid and the rest use mobile alarm (38.0\%) and TV/Radio (8.1\%). The respondents reported signs and symptoms of adverse reactions to their treatment (side effect of HAART medication symptoms ) like fever $9.9 \%$, vomiting/nausea $8.6 \%$, head ache $9.4 \%$, lack of sleep $4.4 \%$, loss of appetite $1.0 \%$, skin problem $4.5 \%$. Considering the self reported source of HIV infection, husband $42.1 \%$, Wife $2.1 \%$, unsafe sex $17.8 \%$ and $38 \%$ said "I don't know". Most respondents (97\%) were detected as being HIV positive before two years.

\subsubsection{Factors Associated with Level of Adherence}

Table 4. Final logistic regression model that predictor Level of adherence dose time, Mekelle Hospital, Mekelle zone, Northern Ethiopia, 2013(n=382).

\begin{tabular}{|c|c|c|c|c|c|c|}
\hline \multirow{2}{*}{ Variable } & \multicolumn{2}{|l|}{ Adherence } & \multirow{2}{*}{ p-value } & \multicolumn{2}{|l|}{ Oddis ratio } & \multirow{2}{*}{$P$ value } \\
\hline & Yes N(\%) & No N(\%) & & COR(95\%CI & AOR(95\%CI) & \\
\hline \multicolumn{7}{|l|}{ Sex } \\
\hline Male & 118(69.0.) & $53(31.0)$ & & 1 & 1 & \\
\hline Female & $185(87.7)$ & $26(12.3)$ & 0.000 & $3.20(1.89,5.39)^{*}$ & $3.81(2.18,6.69)^{*}$ & 0.00 \\
\hline \multicolumn{7}{|l|}{ Age } \\
\hline $18-24$ & $5(71.4)$ & $2(28.6)$ & & 1.00 & & \\
\hline $25-34$ & $113(81.9)$ & $25(18.1)$ & 0.84 & $1.20(0.22,6.65)$ & & \\
\hline $35-44$ & $120(79.5)$ & $31(20.5)$ & 0.22 & $0.66(0.34,1.28)$ & & \\
\hline$>=45$ & $63(75.0)$ & $21(25.0)$ & 0.43 & $0.78(0.41,1.46)$ & & \\
\hline \multicolumn{7}{|l|}{ Occupation } \\
\hline Employed & $65(89.0)$ & $8(11.0)$ & & 1.00 & & \\
\hline Merchant & $155(73.5)$ & $56(26.5)$ & 0.24 & $0.41(0.09,1.81)$ & & \\
\hline Housewife & $24(85.7)$ & $4(14.3)$ & 0.78 & $1.20(0.32,4.540$ & & \\
\hline Have no job & $49(86.0)$ & $8(14.0)$ & 0.49 & $0.56(0.11,2.95)$ & & \\
\hline Others & $10(76.9)$ & $3(23.1)$ & 0.42 & $0.54(0.12,2.42)$ & & \\
\hline \multicolumn{7}{|l|}{ Marital status } \\
\hline Married & $147(80.8)$ & $35(19.2)$ & & 1.00 & & \\
\hline Single & $17(81.0)$ & $4(19.0)$ & 0.37 & $0.758(0.414,1.39$ & & \\
\hline Widowed & $69(79.3)$ & $18(20.7)$ & 0.63 & $0.749(0.228,2.46)$ & & \\
\hline Divorced & $70(76.1)$ & $22(23.9)$ & 0.61 & $0.830(0.410,1.68)$ & & \\
\hline \multicolumn{7}{|l|}{ Educational status } \\
\hline Unable to read and write & $66(71.0)$ & $27(29.0)$ & & 1.00 & 1.00 & \\
\hline Able to read and write & $237(82.0)$ & $52(18.0)$ & 0.023 & $1.87(1.09,3.2)^{*}$ & $2.60(1.43,4.71)^{*}$ & 0.002 \\
\hline \multicolumn{7}{|l|}{ Residence of patient } \\
\hline Rural & $21(80.8 .5)$ & $5(19.2)$ & & & & \\
\hline Urban & $282(79.2)$ & $74(20.8)$ & 0.85 & $0.91(0.33,2.49)$ & & \\
\hline \multicolumn{7}{|l|}{ Average monthly income } \\
\hline$=<500$ & $162(80.6)$ & $39(19.4)$ & & 1.00 & & \\
\hline $501-999$ & $36(80.0)$ & $9(20.0)$ & 0.45 & $0.82(0.48,1.39)$ & & \\
\hline$>=1000$ & $105(77.2)$ & $31(22.8)$ & 0.70 & $0.85(0.37,1.95)$ & & \\
\hline \multicolumn{7}{|l|}{ Living with } \\
\hline Alone & $101(77.1)$ & $30(22.9)$ & & 1.00 & & \\
\hline Family/partner & $150(79.8)$ & $38(20.2)$ & 0.43 & $1.44(0.58,3.58)$ & & \\
\hline Parent & $18(81.8)$ & $4(18.2)$ & 0.65 & $1.23(0.51,2.99)$ & & \\
\hline Children & $34(82.9)$ & $7(17.1)$ & 0.91 & $1.10(0.28,4.18)$ & & \\
\hline \multicolumn{7}{|l|}{ Alcohol use (self report) } \\
\hline Yes & $67(70.5)$ & $28(29.5)$ & & 1.00 & 1.00 & \\
\hline No & $236(82.2)$ & $51(17.8)$ & 0.016 & $1.93(1.13,3.30)^{*}$ & $1.69(0.96,2.95)$ & 0.07 \\
\hline
\end{tabular}

*the variable shows an association with adherence at $\mathrm{p}$ value $<0.05$. 
Different factors were assessed for their association with level of adherence using bivariate logistic regression. On bivariate logistic regression sex of the study participants, educational status and alcohol use were found to be associated with adherence at $p$ value less than 0.05 . But on multivariate logistic regression only sex and educational status of the study participants were associated with adherence. Females were $3.2(1.89,5.39)$ times more likely to be adhered than males. Study participants who can read and write were $2.6(1.09,3.2)$ times more likely to be adhered than those who can't read and write (Table 4).

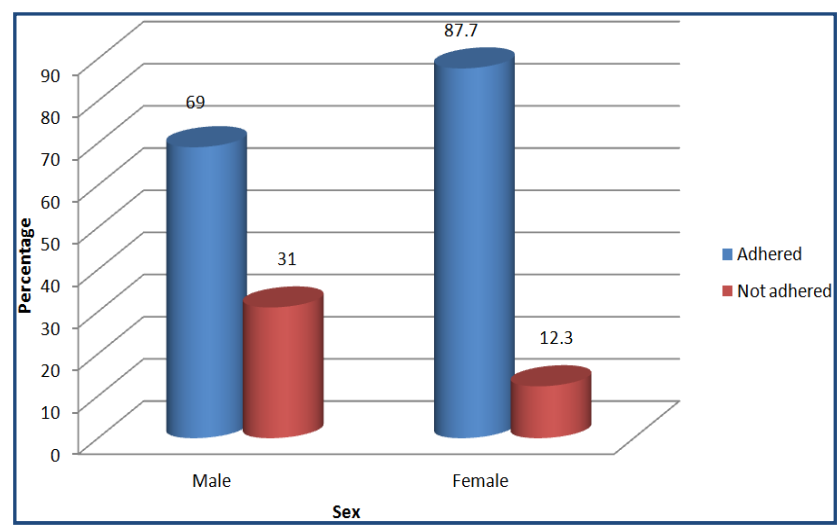

Figure 1. Association of sex with adherence, Mekelle Hospital, Mekelle zone, Northern Ethiopia, 2013(n=382).

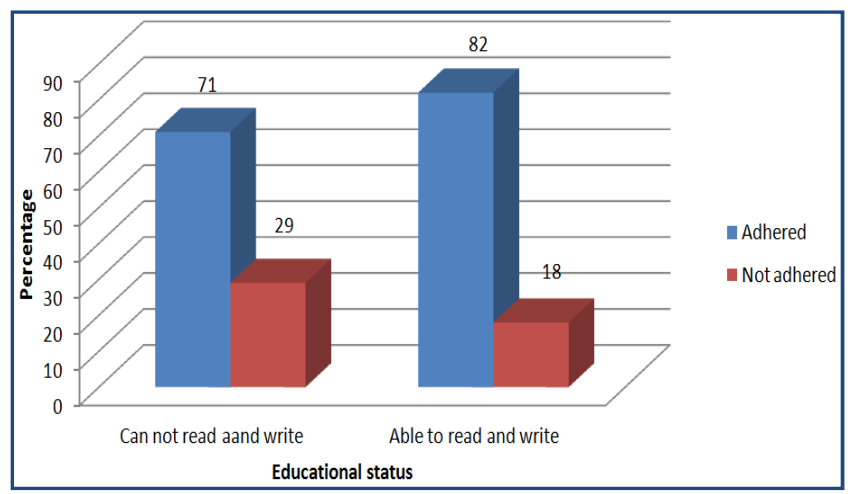

Figure 2. Association of educational status with adherence, Mekelle Hospital, Mekelle zone, Northern Ethiopia, 2013(n=382).

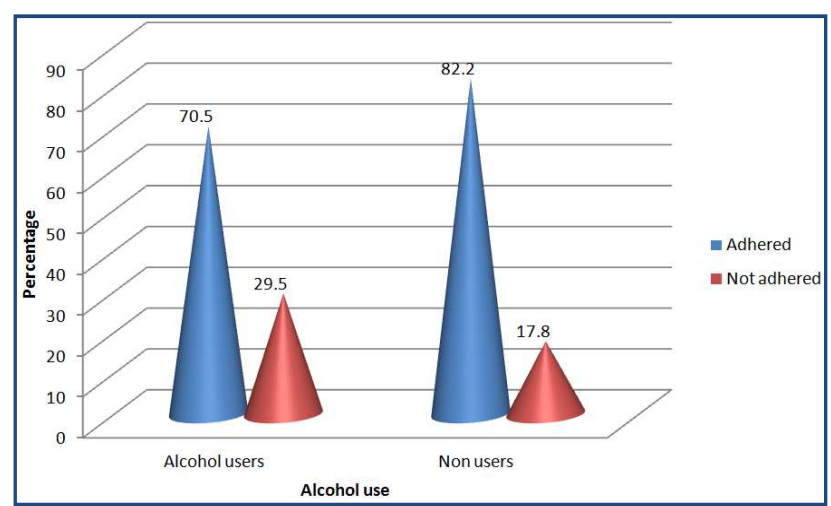

Figure3. Association of alcohol use with adherence, Mekelle Hospital, Mekelle zone, Northern Ethiopia, 2013(n=382)
Study participants who can read and write were more likely to be adhered than individuals who can't read and write. Around $82 \%$ of educated individuals were adhered. But only $71 \%$ of individuals among those who can't read and write were adhered. So, educational status was an important predictor of adherence (Fig. 2).

\subsection{Discussion}

This study has assessed the level of adherence and factors contributing to it. The level of adherence that we found from this study was $78.3 \%$. Considering the WHO recommendation of $95 \%$, this result is still low [9]. The level of adherence was comparable with those reported in Addis Ababa (81.2\% and 82.8\%) and South West Ethiopia (79.3\%) [11-13]. This may suggest that adherence in regional setting is slightly lower than central settings. Some studies in resource-rich settings have documented less than $50 \%$ of patients taking all their antiretroviral medications on time and according to dietary instructions $[14,15]$. This was much lower than our report confirming that patients in developing countries can achieve good adherence despite limited resources. Bonolo et al. review 43 articles on adherence to HAART and they found a mean rate of non-adherence of $30.4 \%$, range from $5 \%$ to $67 \%$ [16]. This was much lower than our result con-firming that patients in developing countries can achieve good adherence despite limited resources. Study conducted in South West Ethiopia indicated that level of adherence was $98.8 \%$, which is higher than that we found [17].

In our study, we found that females were more adhered than males. Study done in South Western Ethiopia also indicated that females were more adhered than males [17]. The resulting higher rate of increase in the medication adherence for females than males might be attributed to females believes in self efficacy in whatever they do in order to succeed. This may also be due to the fact that males used stimulants and other social drugs which will affect adherence negatively than females [17]. But study conducted in South and Central Ethiopia and Togo indicated that males were more adhered than females [18,19]. Study conducted in Kenya also found that sex was not significantly associated with level of adherence [20].

We found an association between educational status and level of adherence. Educated participants have more adherence than individuals with lower educational status. This could be due to the reason that educated people typically engage in healthier behavior patterns. Similarly study done in Kenya found that educational status was significantly associated with level of adherence [20]. Study conducted in South Africa found that low socio economic status was not a predictor of adherence for patients with fully subsidized therapy and concluded that adherence in developing countries has been found to be at least as good as adherence in developed countries [21].

We found no association between social support status and level of adherence. But other study indicated social 
support enhance adherence through encouragement, reassurance, reinforcement, systematic cues, motivation, or by masking the effect of stress, anxiety, and depression. Study done in South Western Ethiopia indicated that Patients who reported social support were more likely to be adherent than those who did not [11]. In study conducted in Southwest Ethiopia patients who got family support were 2 times more likely to adhere than those who didn't get family support. Support from the family facilitated adherence by encouraging and helping to remind them to take the treatment [10].

In our study we found that there was no difference in adherence with respect to difference in distance from the health facility. This could be due to the reason that most of the study participants, $82.7 \%$, came from less than $10 \mathrm{~km}$ or they live in the city. So distance could not be the reason for non-adherence. But, study conducted in Southern Ethiopia indicated that the odds of adherence among those who came from short distance was higher than among those who came from long distance [22]. Study conducted in Southern Ethiopia, Welaita sodo Hospital indicated that level of adherence was associated with Food scarcity to take with HAART, source of food for consumption, with who subject lives and depression status [23].

In our study the major reasons given for missing drugs/dose were forgetting, being busy with other things, feeling of sickness and the rest reasons included simply far from home, due to many pills, going to holy water, running out of drug and out of town. In a study conducted in Southwest Ethiopia, the principal reasons reported for skipping doses were running out of medication/drug, being away from home and being busy with other things and the rest reasons include simply forgetting, having no food to take with the medication, fear of side effect and feeling sick or ill at that time [10]. The proportion of participants with good knowledge about adherence, HAART benefits and HAART eligibility was more than half $(55.5 \%)$. For $97.3 \%$ of the patients, their regimen was first line drugs and fitted to their daily routine work. Considering patient-provider relationship, 33.2\% had very good relationship; $45.5 \%$ had good relationship; and $21.3 \%$ were felt they had poor relation on open discussion with their clinicians and with the HAART unit.

\subsection{Limitation of the Study}

As the study design was cross sectional, there may be probability of recall bias as all cross sectional studies. Because the results depend on the responses of the participants and there may be a chance of recall bias. To some extent, over or under estimation of adherence during self-report was another limitation. The other limitation is that respondents might respond ideally rather than what they practically exercise. The study was conducted in a single site.

\section{Conclusion}

The level adherence we found, $78.3 \%$, is still very low considering the WHO recommendation of $95 \%$. Sex and educational status of the study participants were significantly associated with level of adherence with AOR $(95 \% \mathrm{CI})$ of $3.81(2.18,6.69)$ and $2.60(1.43,4.71)$ respectively. Females were 3.81 times more adhered than males. Educational status was also significant predictor of adherence in our study. Study participants who are able to read and write were 2.6 times more adhered than those who are unable to read and write. So, more focus should be given to males and individuals with low educational status to improve level of adherence and to assure the efficacy of HAART in prolonging the life of PLWHA. Adherence is a process, not a single event, and adherence support must, therefore, be integrated into regular clinical follow up. Investigation of factors related with long-term adherence would require longer follow-up than the present study.

\section{Acknowledgement}

We would like to say thanks to SIKKIM Manipal University of Health, Medical\& Technological Science for giving us this chance; to Tigray Regional Health bureau for funding this project and Mekelle hospital for their permission and cooperation during the entire data collection period. Our special thanks and sincere appreciation also go to supervisors, data collectors and study participants for their contribution to the success of the data collection.

\section{Authors' Contribution}

AF and GG designed the study, analyzed the data, drafted the manuscript and critically reviewed the article. All authors read and approved the final manuscript.

\section{References}

[1] Unaids/who: aids epidemic update 2007. geneva, switzerland.

[2] Unaids/who: aids epidemic update. 2009, unaids/09.36e/jc1700e

[3] Ethiopian Federal Ministry of Health HIV/AIDS Prevention and Control Office. Country progress report in HIV/AIDS response. Addis Ababa: Ethiopian Federal Ministry of Health HIV/AIDS Prevention and Control Office, 2012.

[4] Ministry of Health of Ethiopia: Guideline for Implementation of Antiretroviral Therapy in Ethiopia, Addis Ababa Ethiopia. 2005.

[5] Spire B, Duran S, Souville M, et al. Adherence to highly active antiretroviral therapies (HAART) in HIV-infected patients: from a predictive to a dynamic approach. Soc Sci Med 2002;54:1481-96.

[6] Hecht FM, Grant RM, Petropoulos CJ, Dillon B, Chesney MA, Tian H, Hellmann NS, Bandrapalli NI, Digilio L, Branson B, Kahn JO: Sexual transmission of an HIV-1 variant resistant to multiple reverse-transcriptase and protease inhibitors. N Engl J Med 1998, 339(5):307-11. 
[7] Harrigan PR, Hogg RS, Dong WW, et al: Predictors of HIV drug resistance mutations in a large antiretroviral-naive cohort initiating triple antiretroviral therapy. J Infect Dis 2005, 191:339-47.

[8] Paterson DL, Swindells S, Mohr J, Brester M, Vergis E, Squire C, et al: Adherence to protease inhibitor therapy and outcomes in patients with HIV infection. Ann Intern Med 2000, 133:21-30

[9] Singh N, Berman S, Swindells S. Justis JC, Mohr JA, Squier $\mathrm{C}$ and Wegener MM. Adherence of human immunodeficiency virus- infected patient to antiretroviral therapy. Clinical Infectious Diseases. 1999; 29:824-830.

[10] Tiyou et al. Predictors of adherence to antiretroviral therapy among people living with HIV/AIDS in resource limited setting of southwest Ethiopia, AIDS Research and Therapy $2010,7: 39$

[11] Alemayehu A, Kifle W, Sofonias G, Belaineh G, Kebede D. Predictors of adherence to antiretroviral therapy among HIVinfected persons: a prospective study in Southwest Ethiopia, BMC Public Health. 2008; 8:265.

[12] Tadios Y, Davey G: Antiretroviral treatment adherence and its correlates among people living with HIV/AIDS on highly active antiretroviral therapy in Addis Ababa, Ethiopia. EMJ 2006, 44(2):237-244.

[13] Mengesha A, Worku A: Assessment of antiretroviral treatment among HIV infected persons in the Ministry of Defense Hospitals. AAU; MPH Thesis 2005

[14] Carrieri P, Cailleton V, Le Moing V, Spire B, Delllanonica P, Bouvet E, Raffi F, Journot V, Moatti JP, APROCO study group The dynamic of adherence to highly active antiretroviral therapy: Results from the French National APROCO cohort. J Acquir Immune Defiic Syndr. 2001;28:232-39.

[15] Schonnesson LN, Diamond WPM, Michael Ross, Williams M, Bratt G. Baseline predictors of three types of antiretroviral therapy (ART) adherence: A 2-year follow-up. AIDS Care. 2006;18:246-253.
[16] Bonolo PF, César CC, Acurcio FA, et al: Non-adherence among patients initiating antiretroviral therapy: a challenge for health professionals in Brazil. AIDS 2005, 19(suppl 4):s5s13.

[17] Ejigu et al. Anti-retroviral therapy adherence and its determinants among adult patients living with HIV/AIDS in South West Ethiopia: a facility-based cross sectional study, Gaziantep Med J 2014;20(1):52-58.

[18] Beyene KA, Gedif T, Gebre-Mariam T, Engidawork E. Highly active antiretroviral therapy adherence and its determinants in selected hospitals from south and central Ethiopia. Pharmacoepidemiol Drug Saf 2009;18(11):1007-15.

[19] Potchoo Y, Tchamdja K, Balogou A, Pitche VP, Guissou IP, Kassang EK. Knowledge and adherence to antiretroviral therapy among adult people living with HIV/AIDS treated in the health care centers of the association "Espoir Vie Togo" in Togo, West Africa. BMC Clin Pharmacol 2010;10:11.

[20] Nyambura A. Factors that influence non-adherence to antiretroviral therapy (ART) among human immunodeficiency virus and acquired immune deficiency syndrome (HIV/ AIDS) patients in Kenya, Kenyatta University, Kenya. Department Of Public Health, 2009;68-71.

[21] Orrell C, Bangsberg DR, Badri M, Wood R (2003) Adherence is not a barrier to successful antiretroviral therapy in South Africa. AIDS 17: 1369-1375.

[22] Endrias Markos, Alemayehu Werku, Gail davey. adherence to ART in PLWHA at Yirgalem Hospital, South Ethiopia, Ethio.J.health Dev2008;22(2).

[23] Alagaw A, Godana W, Taha M,Dejene T (2013) Factors Associated with Antiretroviral Treatment Adherence among Adult Patients in Wolaita Soddo Hospital. J Trop Dis 1: 125. doi: 10.4172/2329-891X.1000125. 